\title{
Persistent Subretinal Fluid: Wait or Treat?
}

\author{
Ertugrul Tan Yassa, ${ }^{1}$ (1) Berker Bakbak² \\ ${ }^{1}$ Department of Ophthalmology, Asya Eye Medical Centre, Istanbul, Turkey \\ ${ }^{2}$ Department of Ophthalmology, Selcuk University Faculty of Medicine, Konya, Turkey
}

\begin{abstract}
Persistent subretinal fluid (SRF) may occur even after successful surgery for rhegmatogenous retinal detachment (RRD). In most cases, persistent SRF resolves spontaneously within a year, but persistent SRF may cause poor central vision, photoreceptor damage, and the irreversible loss of visual function. Therefore, a variety of interventions have been developed to manage persistent SRF, including the prophylactic use of steroids. As far as we know, an intravitreal steroid injection has never been used in the treatment of persistent SR. This report is a description of steroid treatment used in the case of a 46-year-old male patient with SRF persisting for 15 months after pars plana vitrectomy surgery for the treatment of macula-off RRD. A single-dose intravitreal triamcinolone acetonide (IVTA) injection $(4 \mathrm{mg} / 0.1 \mathrm{~mL})$ was administered; however, no improvement was seen in the lesions. It was concluded that an IVTA injection should be used in a limited fashion in patients with persistent SRF.
\end{abstract}

Keywords: Persistent subretinal fluid, rhegmatogenous retinal detachment, visual dysfunction.

\section{Introduction}

Persistent subretinal fluid (SRF) may be observed even after successful surgery for rhegmatogenous retinal detachment (RRD); the incidence of this well-known phenomenon varies in the literature (I). Persistent SRF after successful RRD surgery has been reported to occur in $47 \%$ to $100 \%$ of cases of macula-off retinal detachment (I-3). Long duration of persistent SRF after RRD surgery is probably multifactorial. Possible causes include buckling surgery, cryocoagulation, and the high viscosity of SRF due to long-standing retinal detachment (2). Other reasons may be the breakdown of the blood-retinal barrier, and surgical trauma to the retinal pigment epithelium-Bruch's membrane complex (3).

In most cases, persistent SRF disappears spontaneously within I year (4). However, delayed absorption of SRF may not occur in some cases. This case is presented as an example of steroid treatment in a patient with persistent SRF.

\section{Case Report}

A 46-year-old male patient presented with SRF persisting for 15 months after experiencing a right superior maculaoff RRD. Pars plana vitrectomy surgery with sulfur hexafluoride (SF6) gas was performed. Resorption of the peripheral SRF was achieved within I month. His right visual acuity was 20/40 and the patient had metamorphopsia. Optical coherence tomography of the right eye revealed multiple, subretinal, bleb-like lesions beneath the fovea (Fig. I). The lesions were demonstrated to be only minimally hyperfluorescent, with no leakage or staining. The patient's findings remained stable for 15 months. A single-dose intravitreal triamcinolone acetonide (IVTA) injection $(4 \mathrm{mg} / 0.1 \mathrm{~mL})$ was performed; however, no improvement in the lesions was seen.

\section{Discussion}

While several studies have concluded that persistent SRF delays visual recovery without affecting one's final outcome

Address for correspondence: Ertugrul Tan Yassa, MD. Department of Ophthalmology, Asya Eye

Medical Centre, Istanbul, Turkey

Phone: +90 2125939700 E-mail: ertugrultanyassa@yahoo.com

Submitted Date: April 11, 2018 Accepted Date: July 02, 2018 Available Online Date: July 12, 2018

${ }^{\oplus}$ Copyright 2018 by Beyoglu Eye Training and Research Hospital - Available online at www.beyoglueye.com 


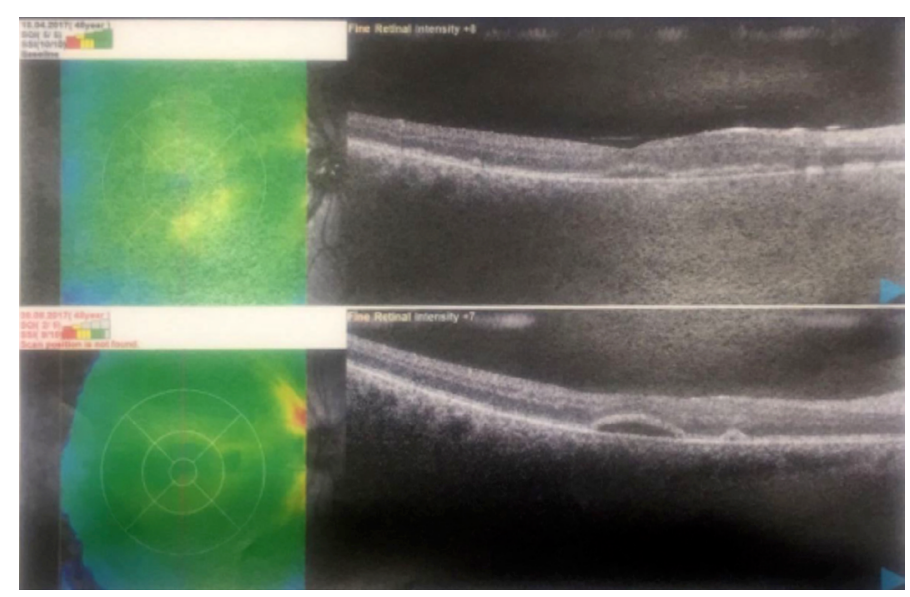

Figure I. Optical coherence tomography of the right eye revealed multiple, subretinal, bleb-like lesions beneath the fovea.

$(I, 5)$, patients with persistent SRF-such as in our case-have cause for complaint due to poor central vision and metamorphopsia. Furthermore, persistent SRF may cause photoreceptor damage and the irreversible loss of visual function (6). As a result, several interventions have been used to manage persistent SRF. First, Koinzer et al. (7) found that selectively damaging retinal pigment epithelial cells using a neodymium: yttrium lanthanum fluoride laser is both safe and effective. Second, Itakura et al. (8) demonstrated that persistent SRF can be treated using an intravitreal injection of SF6 gas. Third, Wu et al. (9) noted that an oral dose of 0.5 or I $\mathrm{mg}$ prednisolone/ $\mathrm{kg}$ for 3 days postoperatively lowered the incidence of SRF and facilitated the absorption of SRF. In addition, the patients in that study demonstrated heightened improvement in their best-corrected visual acuity (BCVA) postoperatively. Finally, Mirshahi et al. (I0) reported that the prophylactic injection of single-dose of IVTA at the end of the RD surgery might increase one's final BCVA, despite the presence of persistent SRF. In our case, an intravitreal steroid injection was used I5 months after RRD surgery to treat persistent SRF. As far as we know, an intravitreal steroid injection has never been used in the treatment of persistent SRF that occurred following RRD. Our patient showed no improvement in terms of either optical coherence tomography findings or BCVA following the injection. Therefore, we can conclude that, other than the role that inflammation plays, other mechanisms must exist in this case and an IVTA injection should be used in a limited fashion in patients with persistent SRF occurring after surgery. Further supportive data are required to reveal the role that steroids play in the treatment of persistent SRF.

\section{Disclosures}

Informed consent: Written informed consent was obtained from the patient for the publication of the case report and the accompanying images.

Peer-review: Externally peer-reviewed.

Conflict of Interest: None declared.

Authorship Contributions: Involved in design and conduct of the study (ETY, BB); preparation and review of the study (ETY, BB); data collection (ETY, BB).

\section{References}

I. Kim JM, Lee EJ, Cho GE, Bae K, Lee JY, Han G, et al. Delayed Absorption of Subretinal Fluid after Retinal Reattachment Surgery and Associated Choroidal Features. Korean J Opthalmol 2017;31:402-II. [CrossRef]

2. Hagimura N, lida T, Suto K, Kishi S. Persistent foveal retinal detachment after successful rhegmatogenous retinal detachment surgery. Am J Ophthalmol 2002;133:5 I6-20. [CrossRef]

3. Kim YK, Ahn J, Woo SJ, Hwang DJ, Park KH. Multiple subretinal fluid blebs after successful retinal detachment surgery: incidence, risk factors, and presumed pathophysiology. Am J Ophthalmol 2014;157:834-4I. [CrossRef]

4. Kang SW, Kim JH, Shin WJ, Kim Jl. Subretinal fluid bleb after successful scleral buckling and cryotherapy for retinal detachment. Am J Ophthalmol 2008; | 46:205-10. [CrossRef]

5. Ricker LJ, Noordzij LJ, Goezinne F, Cals DW, Berendschot TT, Liem AT, et al. Persistent subfoveal fluid and increased preoperative foveal thickness impair visual outcome after maculaoff retinal detachment repair. Retina 2011;31:1505-12. [CrossRef]

6. Veckeneer M, Derycke L, Lindstedt EW, van Meurs J, Cornelissen M, Bracke M, Van Aken E. Persistent subretinal fluid after surgery for rhegmatogenous retinal detachment: hypothesis and review. Graefes Arch Clin Exp Ophthalmol 2012;250:795802. [CrossRef]

7. Koinzer S, Elsner H, Klatt C, Pörksen E, Brinkman R, Birngruber R, et al. Selective retina therapy (SRT) of chronic subfoveal fluid after surgery of rhegmatogenous retinal detachment: three case reports. Graefes Arch Clin Exp Ophthalmol 2008;246: I373-8. [CrossRef]

8. Itakura $\mathrm{H}$, Kishi $\mathrm{S}$. Intravitreal injection of $0.3 \mathrm{ml}$ of SF6 gas for persistent subfoveal fluid after scleral buckling for rhegmatogenous retinal detachment. Graefes Arch Clin Exp Ophthalmol 2009;247: I 147-50. [CrossRef]

9. Wu JS, Lin CJ, Hwang JF, Chen SN. Influence of systemic steroids on subretinal fluid after scleral buckle surgery for maculaoff retinal detachment. Retina 2011;31:99-104. [CrossRef]

10. Mirsahi A, Karkhaneh R, Zamani Amir J, Movassat M, Azadi P. Influence of intravitreal triamcinolone acetonide injection in scleral buckling surgery for macula-off retinal detachment. Ophthalmic Res 2014;52:160-4. [CrossRef] 